\title{
A simple analytical model for burr type prediction in drilling of ductile materials.
}

\author{
doi:10.1016/j.jmatprotec.2012.11.030
}

Keywords: burr type prediction, analytical model, drilling.

Highlights

1- A modelization of sheared volume at drill exit is proposed

2- Existence of a critical thickness of remaining part to be drilled is detailed

3- Its consequences on final burr type are explained

4- The global model is experimentally validated

Stéphane Segonds*, Jacques Masounave ${ }^{(1)}$, Victor Songmene, Christian Bès

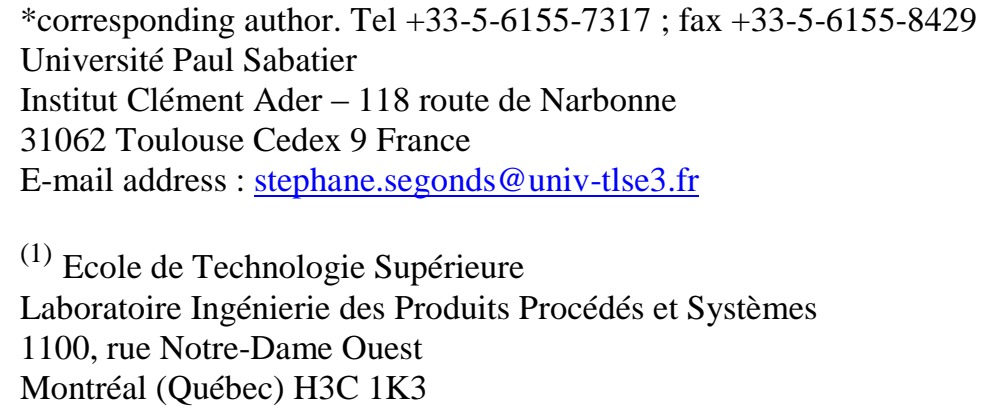

\begin{abstract}
This paper proposes a new analytical model to predict the type of burr at drilling exit. The model is based on the theory of slip-planes and is specially developed to predict burr type formation in drilling of ductile materials. First the analytical model is setup, based on mechanical and geometrical considerations. Then it has been validated through experimental drilling tests on aeronautical aluminum by predicting burr type and thickness. The experimental results show that the model is suitable in the drilling of ductile materials and its validity domain has been established.
\end{abstract}




\section{Introduction}

Burr apparition at the exit of drilled holes significantly affects productivity since it makes deburring a necessary operation. Burr elimination may induce a 30\% cost overrun and may often be manually done [1] [2]. In order to limit or suppress deburring operation, burr size must be decreased as possible. The modes of burr formation in exit of drilling as well as the influential parameters have already been studied through empirical methods, based on experimental observations,. In [3], the authors give qualitative information on how to reduce burr size, on cutting angles and cutting condition and in [4] and [5] the burr formation stages are detailed, giving indications on the influence of cutting angles on final bur height. Theses papers do not directly deal with the specific problem of drilling. A semi analytical model is presented in [6] by dividing a 3,175mm drill cutting edge in 50 segments in order to determine the position of the segment at burr cap removal. This quite complex study has been validated on one specific drill geometry. The method of the finite elements has also been applied to the study and the modeling of this phenomenon [7] [8], and burr formation has already been studied and modeled, especially in feed direction [9]. All the difficulty in a finite elements approach is to define realistic contact tool/ part conditions and material behavior while cutting. However, burr formation in drilling process has not been described from an easy to use analytical point of view. So this study presents a model of exit burr formation in drilling of ductile materials based on the slip planes theory and a threshold to predict type B or $\mathrm{C}$ of burr formation is set up.

\section{Burr formation model}

\subsection{Context}

Burr is usually described by its height and its thickness, tagged as $h_{0}$ and $b_{g}$ for example in [10] and [11]. Other geometrical parameters may be necessary to characterize more precisely the burr geometry, see for example $r_{f}$ and $b_{f}$ in [11]. Others completing geometrical measurable parameters, burr shape (with or without cap, flash etc) can be examined to qualify burr from a morphological point of view. The present study focuses on the parameters that are burr type and burr thickness. The burr type classification detailed in [12] is used along this paper:

Type A : no or very small burr.

Type B : burr with cap burr.

Type C : burr with burn-off marks

In [12], formation of different types of burrs is studied and geometry of the drill has been shown to have an important role on formation of type A, B or C burr [12]. It has also been put in light that type $\mathrm{B}$ or $\mathrm{C}$ formation should be avoided since they are the most difficult types of burrs to remove. So the present study focuses more precisely on prediction of type $\mathrm{B}$ or $\mathrm{C}$ of burr apparition. A threshold allowing knowing if type $\mathrm{B}$ or $\mathrm{C}$ will be produced is setup knowing the machining context: drill geometry, machining conditions and part material. 


\subsection{Modelisation}

Drill is assumed to be perfectly sharp and rigid and the study is relative to ductile material that is meaning that burr formation is without fracture.

As the drill moves toward the part, the distance between the cutting edge and the exit surface decreases. Obviously, there is a critical distance noted bcrit, under which cutting is not possible. The value of bcrit corresponds to the value of $b$ (see figure 1) for which cutting forces induce a plastic deformation of the part remaining to be drilled: rigidity of the part to be drilled is not high enough to support cutting force. To determine this distance, the drilling studied configuration is presented on figure 1, illustrates different angles and quantities used along the paper.
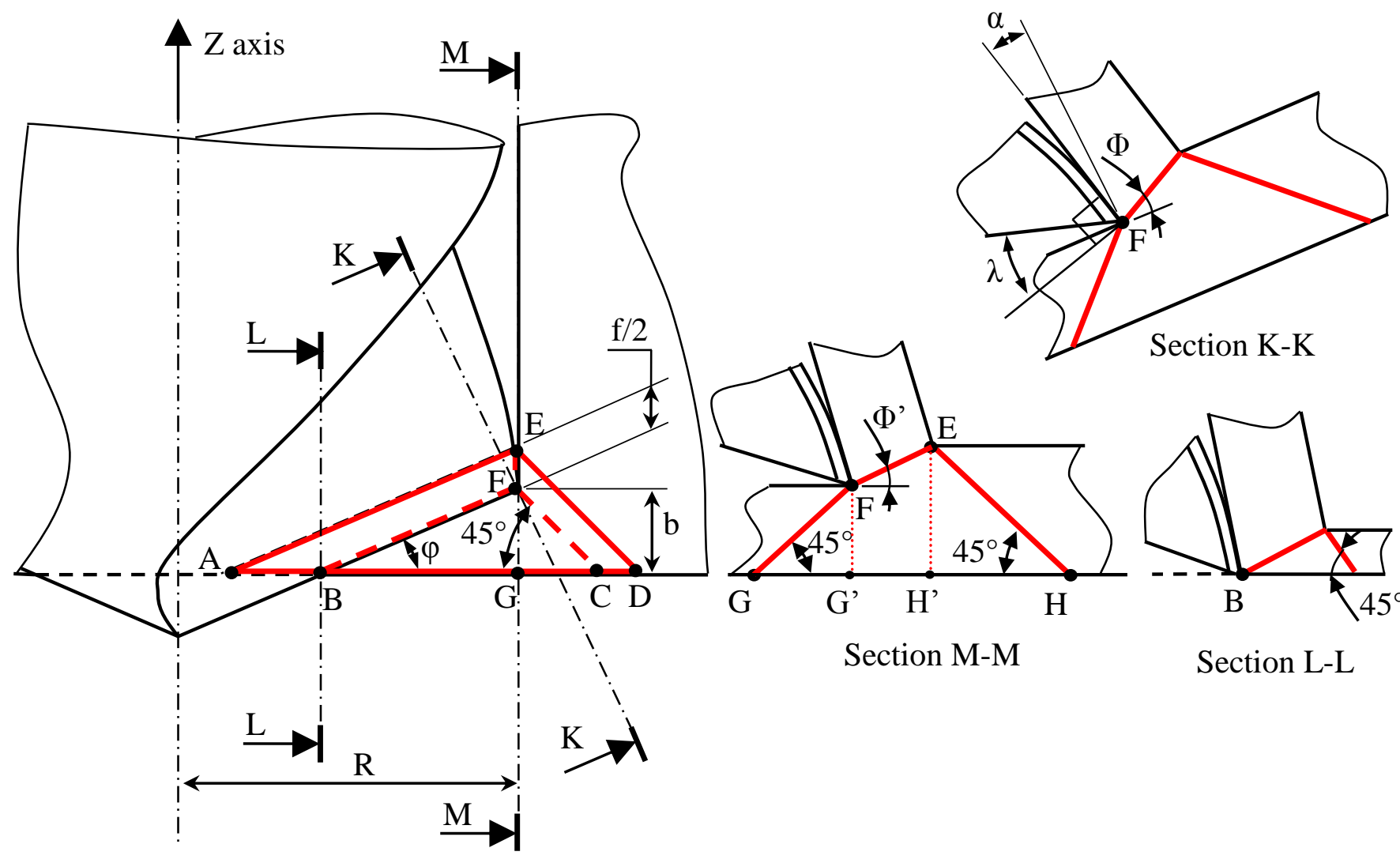

Section M-M

Section L-L

Figure 1: Scheme for burr thickness determination 
Nomenclature:

f feed rate $\quad(\mathrm{mm} / \mathrm{rd})$

$\mathrm{R} \quad$ drill radius (mm)

R1 drill radius for pre drilling (mm)

b height before complete exit drill (mm)

bcrit critical value of height (mm)

$\varphi \quad$ complementary drill point angle $\quad\left({ }^{\circ}\right)$

$\Phi \quad$ shear angle $\quad\left(^{\circ}\right)$

$\Phi$ ' projection of $\Phi$ in M-M section $\quad\left(^{\circ}\right)$

$\alpha \quad$ rake angle $\quad\left({ }^{\circ}\right)$

$\lambda \quad$ normal clearance angle $\quad\left(^{\circ}\right)$

Oi $\quad \mathrm{i} \in[1,6]$ angle between $\mathrm{Si}$ and $\mathrm{Z}$ axis $\quad\left({ }^{\circ}\right)$

$\Theta \sigma \quad$ angle between compression load direction and $\mathrm{Z}$ axis $\quad\left({ }^{\circ}\right)$

$\Theta \tau \quad$ angle between shear load direction and $\mathrm{Z}$ axis $\quad\left({ }^{\circ}\right)$

Si $\quad \mathrm{i} \in[1,6]$ surface $\mathrm{i}$ of the sheared volume $\quad\left(\mathrm{mm}^{2}\right)$

$\mathrm{Fz} \quad$ cutting force along $\mathrm{Z}$ direction $\quad(\mathrm{N})$

бy part material yield strength $\quad$ (MPa)

$\sigma \quad$ normal stress on S1 $\quad$ (MPa)

$\tau \quad$ shear stress on $\mathrm{S} 1 \quad$ (MPa)

$\kappa \quad$ part material plasticity constraint $\quad(\mathrm{MPa})$

Due to geometrical considerations, relation between $\Phi$ and $\Phi^{\prime}$ is presented in equation 1 . The shear angle $\Phi$ can be determined by the equation 2, established by Lee and Shaffer [13].

$$
\begin{array}{ll}
\frac{\tan (\Phi)}{\tan \left(\Phi^{\prime}\right)}=\cos (\varphi) & \text { Eq } 1 \\
\Phi=45+\alpha-\lambda & \text { Eq } 2
\end{array}
$$

Experimental and analytical studies [9] and [14] have shown that burr formation in feed direction is caused by the stresses in the shear plane. The shear and normal stresses are considered uniform in the shear plane $\mathrm{S} 1$ (see figure 2). The cutting edge is represented by BF line and the rake and clearance angles are also considered as constants along BF line.

Since the exit surface is free from external stresses, the slip planes are inclined to the exit surface at $45^{\circ}$ according to the theory of plasticity [15] and [16]. Slip surfaces S2 to S6 are the boundaries of the tensile area. The sheared studied volume is presented on figure 2. 


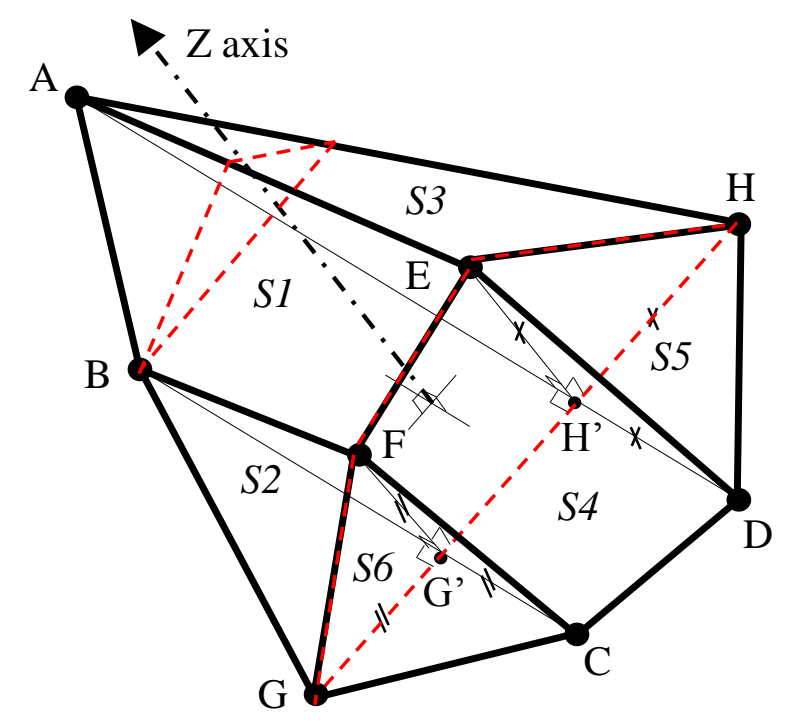

Figure 2: 3D scheme of the sheared volume

Surface ABFE is named S1, it corresponds to the sheared surface due to the drilling cutting forces. Surface ABGCDH corresponds to the surface where the drill exits. Due to geometrical properties of the studied configuration $G^{\prime} F=G^{\prime} G=G^{\prime} C=b$ and $H^{\prime} E=H^{\prime} H=H^{\prime} D=b+f / 2$.

Then equations of surfaces S1 to S6 are determined from geometrical properties of figures 1 and 2 as presented in equations 3 :

$$
\begin{aligned}
& \mathrm{S} 1=\frac{\mathrm{f}}{2 * \sin \left(\Phi^{\prime}\right)} *\left(\frac{\mathrm{b}}{\sin (\varphi)}+\frac{\mathrm{f}}{4 * \tan (\varphi)}\right) \\
& \mathrm{S} 2=\frac{\mathrm{b}^{2}}{\sqrt{2}} * \sqrt{\left(\frac{1}{\tan (\varphi)}\right)^{2}+\frac{1}{2}} \\
& \mathrm{~S} 3=\frac{\left(\mathrm{b}+\frac{\mathrm{f}}{2}\right)}{\sqrt{2}} * \sqrt{\left(\frac{2 * \mathrm{~b}+\mathrm{f}}{2 * \tan (\varphi)}\right)^{2}+\left(\frac{\mathrm{b}+\frac{\mathrm{f}}{2}}{\sqrt{2}}\right)^{2}} \\
& \mathrm{~S} 4=\left(2 * \mathrm{~b}-\frac{\mathrm{f}}{2}\right) * \frac{\mathrm{f}}{2 \sqrt{2} * \tan \left(\Phi^{\prime}\right)} \\
& \mathrm{S} 5=\frac{\sqrt{3}}{2} *\left(\mathrm{~b}+\frac{\mathrm{f}}{2}\right)^{2} \\
& \mathrm{~S} 6=\frac{\sqrt{3} * \mathrm{~b}^{2}}{2}
\end{aligned}
$$


Angles $\Theta i$ between the normal to the surface $\mathrm{Si}$ and $\mathrm{Z}$ axis (see figure 1 and 2) can also be geometrically determined. Knowing that all the angles $\Theta i$ are in a range from 0 to $90^{\circ}$, they can be determined by the following equations 4 .

$$
\begin{aligned}
& \tan (\theta 1)=\frac{\tan (\varphi)}{\cos (\alpha)} \\
& \tan (\theta 2)=\frac{1}{\cos (\varphi)} \\
& \tan (\theta 3)=\frac{1}{\cos (\varphi)} \\
& \tan (\theta 4)=\frac{1}{\cos \left(\Phi^{\prime}\right)} \\
& \tan (\theta 5)=\sqrt{2} \\
& \tan (\theta 6)=\sqrt{2}
\end{aligned}
$$

\subsection{Model for burr thickness prediction \\ 2.3.1. Mechanical model}

Loading on the studied volume presented in figure 1 and 4 is due to the cutting phenomenon and can been decomposed in a normal stress $\sigma$ and a shear one $\tau$, applied on surface S1 see figure 3 .

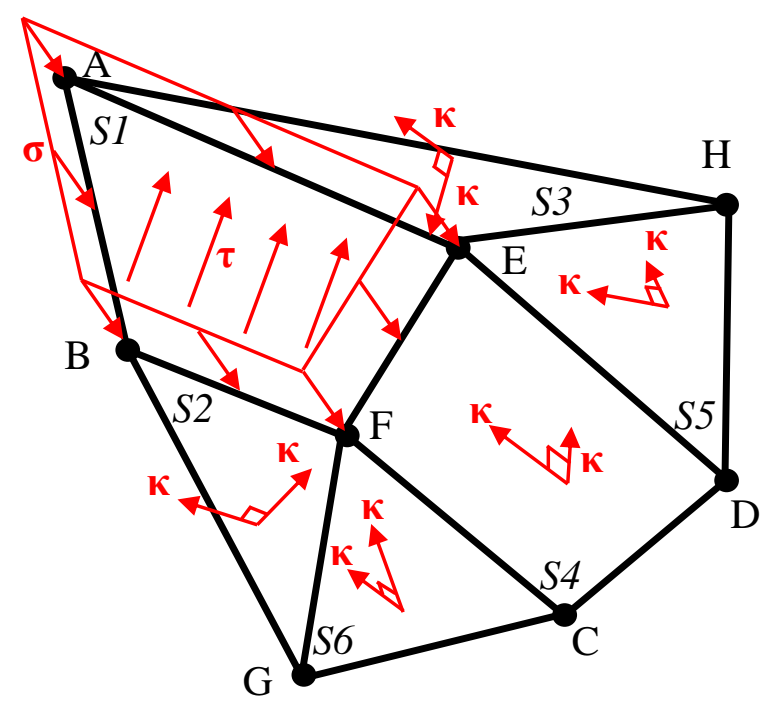

Figure 3: Loadings on the studied sheared volume

Since normal stress is directed on the normal to $S 1$, then angle $\Theta \sigma$ between normal stress direction on $\mathrm{S} 1$ and $\mathrm{Z}$ axis is $\theta \sigma=\theta 1$. Shear stress is directed perpendicularly to the cutting edge, so to BF line (see figure 1) in $\mathrm{S} 1$ and $\mathrm{BF}$ is along the radius of the hole, then angle $\Theta \tau$ between shear direction and $\mathrm{Z}$ axis is $\theta \tau=90-\Phi^{\prime}$ 
The exit surface is free from external stresses and tension is expected in surfaces S2 to S6 due to the stresses applied on S1. When bcrit value is attained normal and shear stresses in S2 to S6 are equal to the value of plasticity $\kappa$, see figure 3 . Shear stress is directed perpendicularly to the normal stress and in a plan that is perpendicular to $\mathrm{Z}$ direction. Value of plasticity $\kappa$ is determined from $\sigma y$, yield strength of workpiece material, according to the Mises criterion as $\kappa=\frac{\sigma y}{\sqrt{3}}$

Then, equation of the force balance of sheared volume presented on figure 3 with respect to the Z-axis can be written as:

$$
\begin{aligned}
& \kappa *((\sin (\theta 2)+\cos (\theta 2)) * \mathrm{~S} 2+(\sin (\theta 3)+\cos (\theta 3)) * \mathrm{~S} 3+(\sin (\theta 4)+\cos (\theta 4)) * \mathrm{~S} 4+ \\
& (\sin (\theta 5)+\cos (\theta 5)) * \mathrm{~S} 5+(\sin (\theta 6)+\cos (\theta 6)) * \mathrm{~S} 6)=(\sigma * \cos (\theta \sigma)-\tau * \cos (\theta \tau)) *
\end{aligned}
$$

For a given drilling configuration including tool geometry and part material characteristics, solving this equation conduce to determine the limit distance bcrit.

When the drill attains bcrit value, the cutting forces that are necessary to cut the material become too high in regard of the subsisting material rigidity. Then cutting forces cause plastic deformation of the workpiece material which is transformed into burr.

Initial height of studied volume (H'E distance see figure 2) becomes the burr thickness after deformation and the value of bcrit corresponds to the value of the burr thickness.

\subsubsection{Loads determination}

For solving the previous equation of force balance, it is preliminary needed to evaluate $\sigma$ and $\tau$ for the studied drilling configuration. These two parameters are evaluated by force measurement during drilling. A predrilled hole (radius R1) is used in order to eliminate forces effect due to the drill web. Fz corresponds to the cutting force along $\mathrm{Z}$ direction, and the sheared area while drilling and before any point of the drill attaining the exit surface is noted $\mathrm{S} 10$. The relations between $\mathrm{Fz}, \sigma$ and $\tau$ coming from force balance with respect to $\mathrm{Z}$ axis are:

$$
(\sigma * \cos (\theta \sigma)-\tau * \cos (\theta \tau)) * \mathrm{~S} 10=\frac{\mathrm{Fz}}{2} \quad \text { Eq } 6
$$

$\mathrm{S} 10=\frac{\mathrm{R}-\mathrm{R} 1}{2 * \cos (\varphi) * \sin \left(\Phi^{\prime}\right)}$

Combining the previous equations 5, 6 and 7 conduces to the expression of an equation combining geometrical drill parameters, $b$ parameter and feed force as follows:

$$
\begin{aligned}
& \kappa *((\sin (\theta 2)+\cos (\theta 2)) * \mathrm{~S} 2+(\sin (\theta 3)+\cos (\theta 3)) * \mathrm{~S} 3+(\sin (\theta 4)+\cos (\theta 4)) * \mathrm{~S} 4+ \\
& (\sin (\theta 5)+\cos (\theta 5)) * \mathrm{~S} 5+(\sin (\theta 6)+\cos (\theta 6)) * \mathrm{~S} 6)=\frac{\mathrm{Fz} * \mathrm{~S} 1 *(\mathrm{R}-\mathrm{R} 1)}{4 * \cos (\varphi) * \sin (\Phi \prime)}
\end{aligned}
$$

In the following part, solution existence for this equation and its effect on bur type is discussed. 


\subsection{Burr type prediction}

The previous part of the study proposes a model allowing determining a critical thickness value under which material part would plastically deform rather than supporting the cutting force. Many works on burr formation put in light the existence of three different types of burr. The further section details conditions of appearance of different burr types.

\subsubsection{Burr type A}

If equation 8 has no solution, that means that as thick as may be the rest of the part under the drill, it is rigid enough to support the cutting force without any plastic deformation. In this case a type A of burr is obtained. Drill cutting edge totally exits the part and it's the secondary cutting edge, at the end of the drill margin, which cuts for the very end of the drilling. Results may differ from a test to another because of drill margin design that is varying between drill manufacturers. Nevertheless, cutting forces become tangential instead of being axial while cutting with main cutting edge, so burr generated in the last turn should be small and rake angle dependant. In this condition cutting force do not tend to make bending the rest of the part to be drilled. These considerations explain the fact that this configuration conduces to a type A of burrs, which is the case that requires the least removal cost.

\subsubsection{Burr type B}

If a bcrit value exists, that means that equation 8 has a solution, burr thickness may be modelized, and this thickness is equal to bcrit $+\mathrm{f} / 2$. Taking in account geometrical considerations, this section provides a modelization of burr type and burr height depending on feed rate. Indeed, the feed rate factor seems to have a high impact on burr type [6] [9] and on burr height.

The reasoning detailed in the previous section may be applied at any moment of the drilling since the drill web has already went out of the part, like presented in figure 4 .

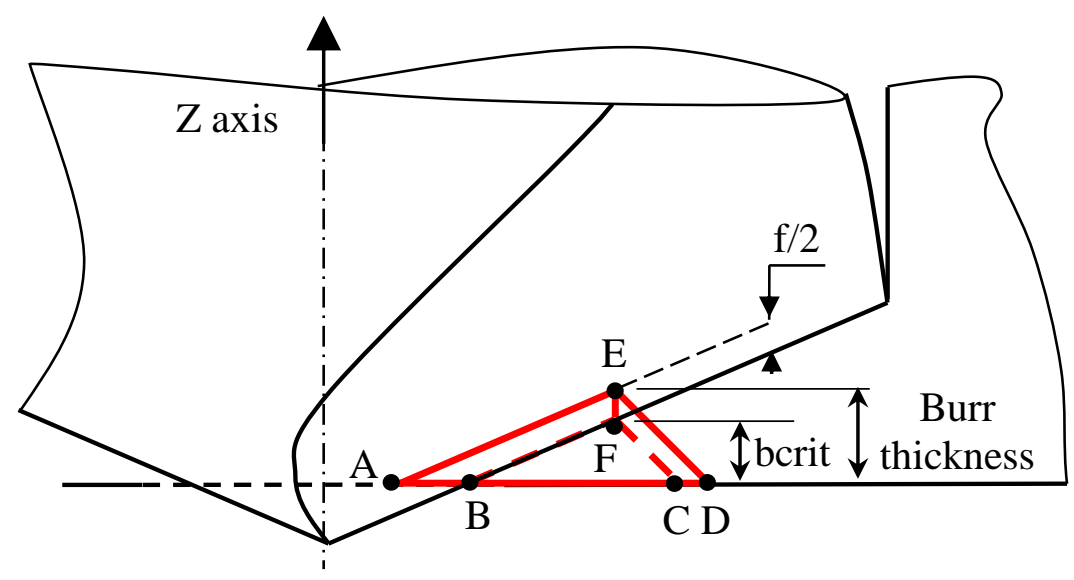

Figure 4: Sheared volume scheme

Then, at any moment of the drill exit, there is a portion of the part remaining under the drill that is not rigid enough to support the cutting force without bending. This part corresponds to the volume studied in the previous section with a height that is equal to bcrit $+f / 2$, see figure 4 . 
Existence of a bcrit value solution of equation 8 implies that half of the feed rate (feed rate / tooth) is smaller than burr thickness and burr formation can be explained as shown on figure 5.

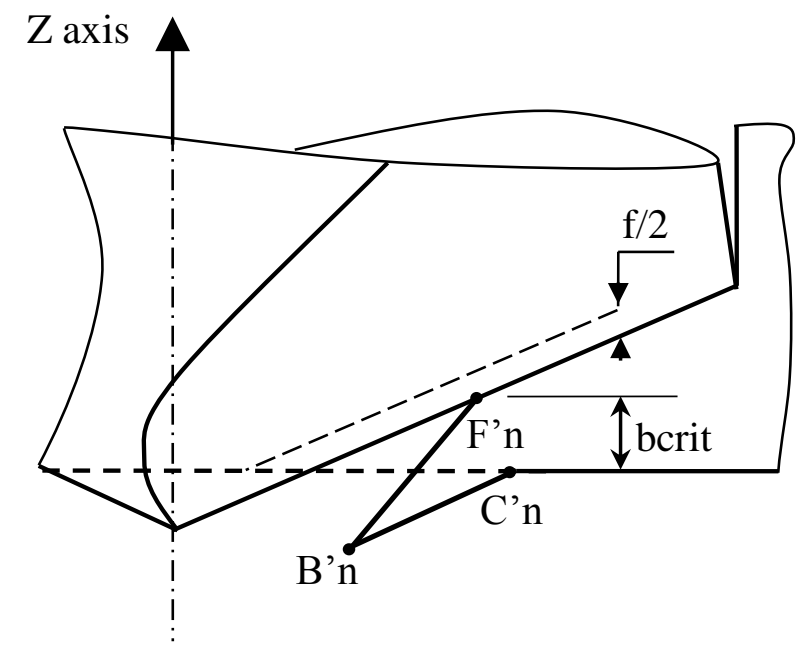

Turn n

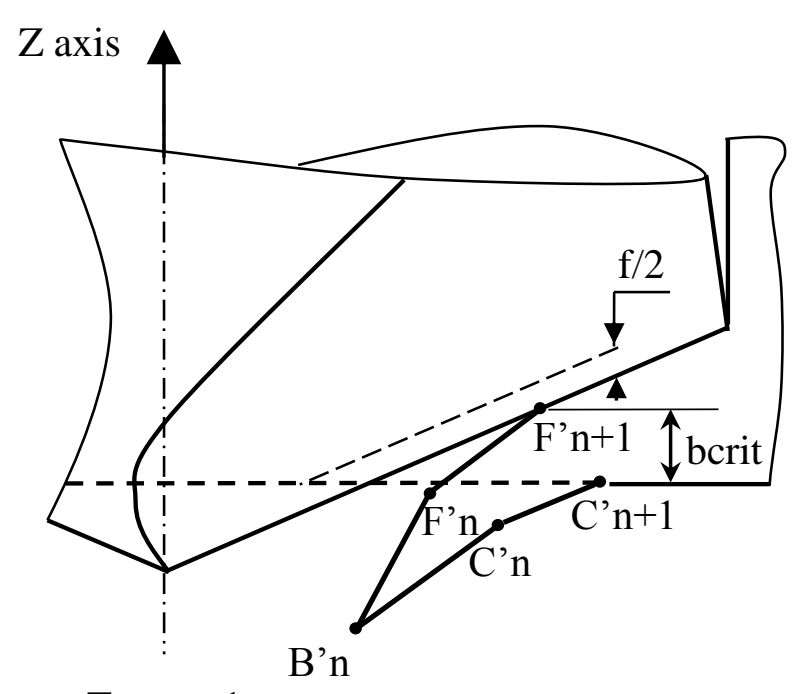

Turn $n+1$

Figure 5: Burr formation at drill exit between turn $n$ and $n+1$

When half of the feed rate is lower than burr thickness value, the burr grows at each turn of the drill because cutting edge cannot pass under the previously created burr. This explains that in these cutting conditions, a type $\mathrm{B}$ or $\mathrm{C}$ of burr is obtained. If drill web pierces the material while exiting the part that conduces to a type $\mathrm{C}$ of burr, in the other case it conduces to a type B.

These conditions, modelizing cutting of the burr at turn $n+1$ while it has been initiated at turn $\mathrm{n}$ is quite difficult. But the proposed model evaluates burr type and thickness knowing machining conditions. From an industrial point of view that is an important information since burr type $\mathrm{B}$ or $\mathrm{C}$ must be avoided as possible, due to the high cost generated by their elimination with deburring operation.

\section{Experimental verification}

\subsection{Experimental context}

Tests have been conducted on a Huron-K2x10 cnc machine, and a Kistler multi-component dynamometer 9255B type has been used for force measurements.

A 19,6 mm thick plate of aeronautical aluminum 2024 T354 was set up on to realize experimental validation tests. This ductile material corresponds to the study case of the presented work. 
The model is point angle, rake angle and feed rate dependant. So different drills with various geometries have been tested as summarized in the table 1

\begin{tabular}{|c|c|c|c|}
\hline Drill & Diameter & Rake angle & Point angle \\
\hline $\mathrm{N}^{\circ} 1$ & $8 \mathrm{~mm}$ & $10^{\circ}$ & $135^{\circ}$ \\
\hline $\mathrm{N}^{\circ} 2$ & $8 \mathrm{~mm}$ & $30^{\circ}$ & $135^{\circ}$ \\
\hline $\mathrm{N}^{\circ} 3$ & $8 \mathrm{~mm}$ & $40^{\circ}$ & $135^{\circ}$ \\
\hline $\mathrm{N}^{\circ} 4$ & $8 \mathrm{~mm}$ & $30^{\circ}$ & $115^{\circ}$ \\
\hline $\mathrm{N}^{\circ} 5$ & $12 \mathrm{~mm}$ & $30^{\circ}$ & $135^{\circ}$ \\
\hline
\end{tabular}

Table 1: Drill geometry

For all the drills, the clearance angle is $10^{\circ}$. Drills have been especially grinded to obtain the specified rake angle.

For each drill, 5 feed rate have tested: 0,0125 - 0,025 - 0,05 - 0,1 - 0,2 $\mathrm{mm} / \mathrm{tr}$ and each test has been repeated twice. The cutting speed for the main tests is a $60 \mathrm{~m} / \mathrm{min}$ speed and all the tests are realized in dry machining. In [6], it is detailed that the effect of cutting speed on burr formation is very less important than other parameters and especially than feed rate and cutting angles effects. Nevertheless cutting speed effect is taken in account by its effect on axial cutting force which is used in the model. Verification is done by also doing a $30 \mathrm{~m} / \mathrm{min}$ and $120 \mathrm{~m} / \mathrm{min}$ test with drill $\mathrm{n}^{\circ} 2$.

Specific force measurement tests have been previously conducted with drills of table 1 after a $4 \mathrm{~mm}$ pre-drilling. This is to evaluate $\mathrm{Fz}$ value needed in equation 8 . Indeed, the loadings on the studied volume (see figure 3 ) have to be evaluated without the effect of the drill web. The tests allowing analyzing burr formation have been conducted without any predrilling. Type B and $\mathrm{C}$ of burr thickness have been measured with a micrometer caliper.

\subsection{Results and analysis}

\subsubsection{Burr type and confrontation to the model prediction}

For each test, the cutting force is for drilling in a $4 \mathrm{~mm}$ predrilled hole. Presented model has been computed by solving equation 8 with the solver function of excel software. For each given configuration the bcrit value has been calculated and when this value exists it is mentioned in the table. The value $\sigma \mathrm{y}$, yield strength of workpiece material is set to $324 \mathrm{MPa}$ as detailed in [17]. Results obtained at $0,2 \mathrm{~mm} / \mathrm{tr}$ feed rate are not detailed in the following tables since, as with $0,1 \mathrm{~mm} / \mathrm{tr}$ feed rate, they always present a burr type $\mathrm{A}$

Following tables 2 present test results conducted at $60 \mathrm{~m} / \mathrm{min}$. 


\begin{tabular}{|c|c|c|c|c|c|}
\hline \multicolumn{2}{|c|}{ Feed rate $(\mathrm{mm} / \mathrm{tr})$} & 0,0125 & 0,025 & 0,05 & 0,1 \\
\hline \multirow{4}{*}{$\mathrm{N}^{\circ} 1$} & $\mathrm{Fz}(\mathrm{N})$ & 50 & 55 & 65 & 110 \\
\hline & $\begin{array}{l}\text { Predicted } \\
\text { - burr type } \\
\text { - bcrit value } \\
\text { - burr thickness }\end{array}$ & $\begin{array}{l}\text { Type B or C } \\
0,016 \\
0,022\end{array}$ & $\begin{array}{l}\text { Type B or C } \\
0,011 \\
0,023\end{array}$ & $\begin{array}{l}\text { Type A } \\
- \\
- \\
\end{array}$ & $\begin{array}{l}\text { Type A } \\
- \\
- \\
\end{array}$ \\
\hline & Observation & & & & \\
\hline & $\begin{array}{l}\text { Measured } \\
\text { - burr type } \\
\text { - burr thickness }\end{array}$ & $\begin{array}{l}\text { Type C2 } \\
0,025\end{array}$ & $\begin{array}{l}\text { Type B } \\
0,029-0,08\end{array}$ & Type A & Type A \\
\hline
\end{tabular}

Table 2a: Experimental and theoretical results with drill $\mathrm{n}^{\circ} 1$

\begin{tabular}{|c|c|c|c|c|c|}
\hline Dril & Feed rate $(\mathrm{mm} / \mathrm{tr})$ & 0,0125 & 0,025 & 0,05 & 0,1 \\
\hline & $\mathrm{Fz}(\mathrm{N})$ & 44 & 50 & 57 & 64 \\
\hline $\mathrm{N}^{\circ} 2$ & $\begin{array}{l}\text { Predicted } \\
\text { - burr type } \\
\text { - bcrit value } \\
\text { - burr thickness }\end{array}$ & $\begin{array}{l}\text { Type B or C } \\
0,013 \\
0,019\end{array}$ & $\begin{array}{l}\text { Type B or C } \\
0,008 \\
0,021\end{array}$ & $\begin{array}{l}\text { Type A } \\
- \\
-\end{array}$ & $\begin{array}{l}\text { Type A } \\
- \\
-\end{array}$ \\
\hline & Observation & & & & \\
\hline & $\begin{array}{l}\text { Measured } \\
\text { - burr type } \\
\text { - burr thickness }\end{array}$ & $\begin{array}{l}\text { Type B } \\
0,022-0,07\end{array}$ & $\begin{array}{l}\text { Type B } \\
0,030-0,08\end{array}$ & $\begin{array}{l}\text { Type A } \\
-\end{array}$ & Type A \\
\hline
\end{tabular}

Table 2b: Experimental and theoretical results with drill $\mathrm{n}^{\circ} 2$

\begin{tabular}{|c|c|c|c|c|c|}
\hline \multicolumn{2}{|c|}{ Feed rate $(\mathrm{mm} / \mathrm{tr})$} & 0,0125 & 0,025 & 0,05 & 0,1 \\
\hline \multirow{4}{*}{$N^{\circ} 3$} & $\mathrm{Fz}(\mathrm{N})$ & 24 & 30 & 37 & 45 \\
\hline & $\begin{array}{l}\text { Predicted } \\
\text { - burr type } \\
\text { - bcrit value } \\
\text { - burr thickness }\end{array}$ & $\begin{array}{l}\text { Type B or C } \\
0,003 \\
0,009\end{array}$ & $\begin{array}{l}\text { Type A } \\
- \\
-\end{array}$ & $\begin{array}{l}\text { Type A } \\
- \\
-\end{array}$ & $\begin{array}{l}\text { Type A } \\
- \\
-\end{array}$ \\
\hline & Observation & & & & \\
\hline & $\begin{array}{l}\text { Measured } \\
\text { - burr type } \\
\text { - burr thickness }\end{array}$ & $\begin{array}{l}\text { Type A } \\
\text { - }\end{array}$ & $\begin{array}{l}\text { Type A } \\
\text { - }\end{array}$ & $\begin{array}{l}\text { Type A } \\
\text { - }\end{array}$ & Type A \\
\hline
\end{tabular}

Table 2c: Experimental and theoretical results with drill $\mathrm{n}^{\circ} 3$ 


\begin{tabular}{|c|c|c|c|c|c|}
\hline Drill & Feed rate $(\mathrm{mm} / \mathrm{tr})$ & 0,0125 & 0,025 & 0,05 & 0,1 \\
\hline & $\mathrm{Fz}(\mathrm{N})$ & 20 & 69 & 84 & 95 \\
\hline $\mathrm{N}^{\circ} 4$ & $\begin{array}{l}\text { Predicted } \\
\text { - burr type } \\
\text { - bcrit value } \\
\text { - burr thickness }\end{array}$ & $\begin{array}{l}\text { Type B or C } \\
0,013 \\
0,019\end{array}$ & $\begin{array}{l}\text { Type B or C } \\
0,010 \\
0,023\end{array}$ & $\begin{array}{l}\text { Type B or C } \\
0,003 \\
0,028\end{array}$ & $\begin{array}{l}\text { Type A } \\
- \\
-\end{array}$ \\
\hline & Observation & & & & \\
\hline & $\begin{array}{l}\text { Measured } \\
\text { - burr type } \\
\text { - burr thickness }\end{array}$ & $\begin{array}{l}\text { Type C2 } \\
0,025\end{array}$ & $\begin{array}{l}\text { Type C2 } \\
0,030\end{array}$ & $\begin{array}{l}\text { Type C2 } \\
0,030\end{array}$ & Type A \\
\hline
\end{tabular}

Table 2d: Experimental and theoretical results with drill $n^{\circ} 4$

\begin{tabular}{|c|c|c|c|c|c|}
\hline Drill & Feed rate $(\mathrm{mm} / \mathrm{tr})$ & 0,0125 & 0,025 & 0,05 & 0,1 \\
\hline \multirow{4}{*}{$N^{\circ} 5$} & $\mathrm{Fz}(\mathrm{N})$ & 60 & 75 & 90 & 125 \\
\hline & $\begin{array}{l}\text { Predicted } \\
\text { - burr type } \\
\text { - bcrit value } \\
\text { - burr thickness }\end{array}$ & $\begin{array}{l}\text { Type B or C } \\
0,007 \\
0,013\end{array}$ & $\begin{array}{l}\text { Type A } \\
- \\
- \\
\end{array}$ & $\begin{array}{l}\text { Type A } \\
- \\
- \\
\end{array}$ & $\begin{array}{l}\text { Type A } \\
- \\
- \\
\end{array}$ \\
\hline & Observation & & & & \\
\hline & $\begin{array}{l}\text { Measured } \\
\text { - burr type } \\
\text { - burr thickness }\end{array}$ & Type A & Type A & Type A & Type A \\
\hline
\end{tabular}

Table 2e: Experimental and theoretical results with drill $\mathrm{n}^{\circ} 5$

(*) the remaining part of burr has fallen while removing the part from the machine

Following table 3 presents the results obtained with drill $\mathrm{n}^{\circ} 1$ at various cutting speed and $0,025 \mathrm{~mm} / \mathrm{tr}$ feed rate. 


\begin{tabular}{|c|c|c|c|c|}
\hline \multicolumn{2}{|c|}{$\begin{array}{l}\text { Cutting speed }(\mathrm{m} / \mathrm{min}) \\
\text { Drill }\end{array}$} & 30 & 60 & 120 \\
\hline \multirow{4}{*}{$\mathrm{N}^{\circ} 2$} & $\mathrm{Fz}(\mathrm{N})$ & 60 & 50 & 40 \\
\hline & $\begin{array}{l}\text { Predicted } \\
\text { - burr type } \\
\text { - bcrit value } \\
\text { - burr thickness }\end{array}$ & $\begin{array}{l}\text { Type B or C } \\
0,013 \\
0,025\end{array}$ & $\begin{array}{l}\text { Type B or C } \\
0,008 \\
0,021\end{array}$ & $\begin{array}{l}\text { Type B or C } \\
0,001 \\
0,013\end{array}$ \\
\hline & Observation & & & \\
\hline & $\begin{array}{l}\text { Measured } \\
\text { - burr type } \\
\text { - burr thickness }\end{array}$ & $\begin{array}{l}\text { Type B } \\
0,030-0,08\end{array}$ & $\begin{array}{l}\text { Type B } \\
0,029-0,07\end{array}$ & $\begin{array}{l}\text { Type C2 } \\
0,022\end{array}$ \\
\hline
\end{tabular}

Table 3: Experimental and theoretical results with drill $\mathrm{n}^{\circ}$ at $0,025 \mathrm{~mm} / \mathrm{tr}$

\subsubsection{Analysis}

\section{Burr type prediction}

In most cases, model predictions fit the observations in terms of burr type prediction.

Indeed with drill $\mathrm{n}^{\circ} 3$ at $0,0125 \mathrm{~mm} / \mathrm{tr}$ feed rate, a B or $\mathrm{C}$ burr type was predicted and type $\mathrm{A}$ was observed. This point may be explained by

- bcrit value is near zero for this configuration, meaning that this configuration is quite in the transient domain between burr appearance and disappearance

- a meticulous observation of the hole edge, presented in figure 6a, confirms that upper face of the remaining burr presents a breaking pattern showing that this configuration is in a transient domain between burr appearance and disappearance, see for difference figure $6 \mathrm{~b}$ showing hole' edge drilled with the same tool at $0,025 \mathrm{~mm} / \mathrm{tr}$ feed rate.

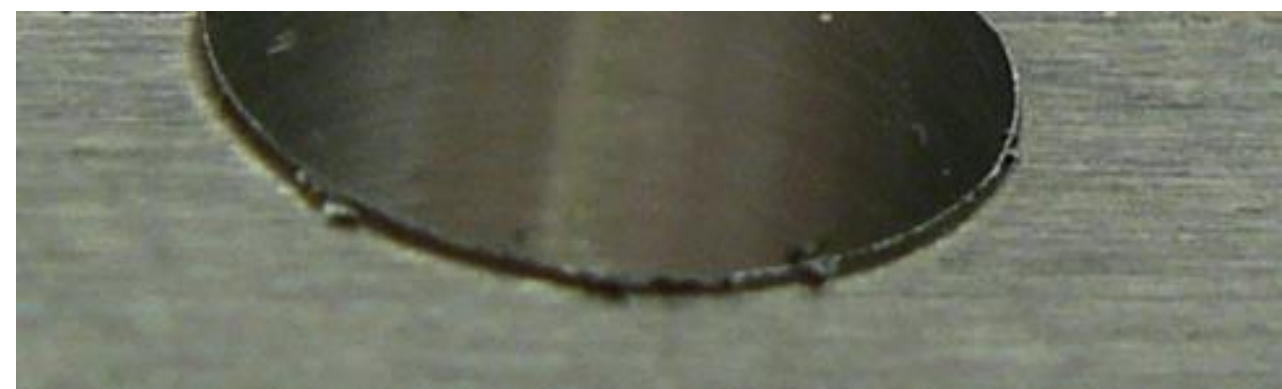




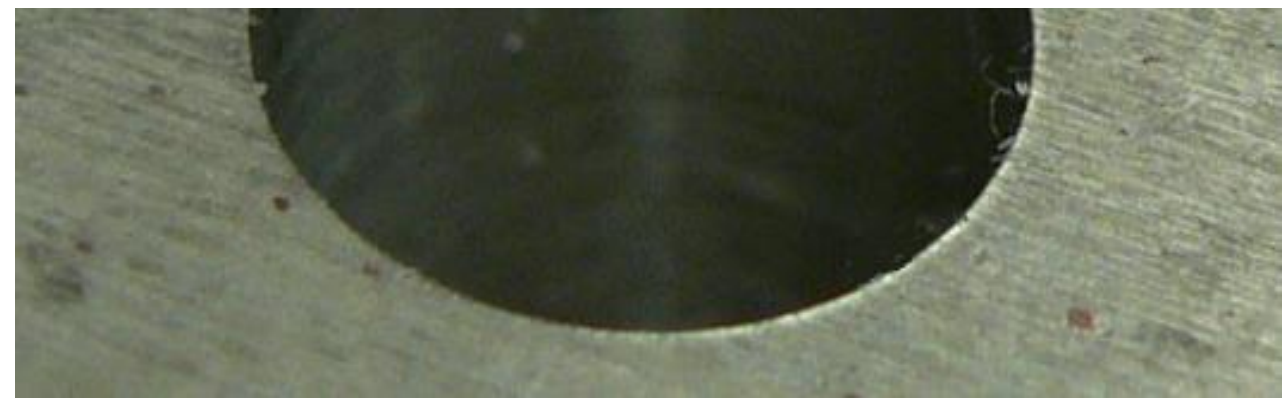

Figure 6: a- Detail of hole' edge (drill $\left.\mathrm{n}^{\circ} 3-0,0125 \mathrm{~mm} / \mathrm{tr}-60 \mathrm{~m} / \mathrm{min}\right)$ b- Detail of hole' edge (drill $\left.\mathrm{n}^{\circ} 3-0,025 \mathrm{~mm} / \mathrm{tr}-60 \mathrm{~m} / \mathrm{min}\right)$

The criterion set by the presented model is a binary one: if bcrit value exits, a burr of type B or $\mathrm{C}$ should exist. The real cutting is not so binary but analyzing the previous case shows that the transient domain can be determined by the model by studying bcrit value

Tables 2 and 3 shows that distinction between burr type B or C 2 cannot be described by this model, and considerations about point angle and cutting speed should be taken in account to explain the phenomenon conducting to a B or C2 burr type. Observed burr types seem coherent since drill $n^{\circ} 4$ is more acute than drill $n^{\circ} 2$ : the more acute is the drill and the easier it is at splitting the burr cap in a $\mathrm{C} 2$ burr.

\section{$\underline{\text { Burr thickness prediction }}$}

Model prediction in term of thickness fits measurements in case of $\mathrm{C} 2$ burr type since predictions and measures are in the same order of magnitude. It is quite different in case of B burr type for which two values are mentioned in tables 2 . The highest value corresponds to the thickness measurement at the periphery of the burr cap, the lowest one corresponds to measurement around the middle, where cap is exploded and looks like C2 burr type, see figure 7.

High thickness value

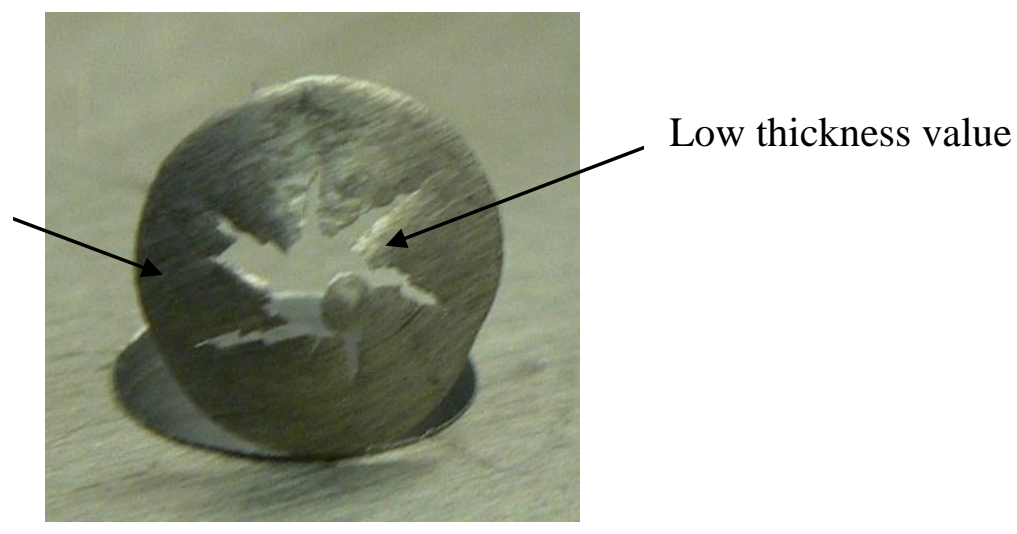

Figure 7: Location of high and low values of thickness measurement

Further study could help determining the reason of this thickness variation but a beginning of explanation could be as follows. At the beginning of the burr formation, in the center, the cutting speed is not high enough to let the drill edge passing under the beginning burr, so its thickness is just equal to bcrit $+\mathrm{f} / 2$ value. But the burr grows at each drill turn and finished to be the thicker at the part that is produced at the end of the drill exit, that is at the periphery. At 
the periphery, cumulated thicknesses due to all previous turns conduce to biggest thickness than in the middle. In the configuration of a burr cap growth, the mechanism should also be different from the studied configuration since cap works more like a membrane or a shell.

\section{Conclusion}

The experimental verification has shown that the model gives reliable theoretical datas regarding burr thickness, and can accurately predict burr type. In comparison with previous works, this study's analytical model considering slip planes theory is based on physical considerations to explain burr formation phenomenon in drilling. Despite a lack of information on precise burr type, the model allows determining cutting conditions and drill geometry in order to get a type 1 of burr which is the one requiring the least removal cost. This kind of approach has already been used in burr prediction in turning, see [9], but it was in an orthogonal cutting context with a semi infinite dimension of the machined part assumption that could not be accepted in drilling. Since the presented model is very different from what have already been developed in drilling, its efficiency can hardly be compared. However, the results concord fully with statements detailed in other experimental studies like [6] or [18]. At very low feed rate, burr eight is the highest and then decreases to its minimum before rising again while feed rate increase. That corresponds to the model prediction since reducing feed rate conduce to bcrit value existence stating a cap appearance prediction, but on the opposite, much increasing feed rate conduce to increase load on remaining part under the drill that produce burr by bending. So there is an optimal feed rate that must be just hight enough to avoid burr cap and not too high to avoid thick drilled part bending and conducing to a high burr.

The proposed model can be used in computer manufacturing systems, to predict burr appearance on the edges of drilled parts. The model can also be used in independent burr expert systems so as to minimize burr formation by choosing optimal cutting conditions.

Subsequent studies on burr modeling should focus on the effects of tool wear on burr development as well as the effect of high cutting speed that should modify burr formation phenomenon. 


\section{REFERENCES}

[1] Gillespie, L.K., 1975. The \$2 billion deburring bill. Manuf. Eng. Manage. 74, 20-21.

[2] Gillespie, L.K., 1979. Deburring precision miniature parts. Prec. Eng. 1, 189-198.

[3] K. Nakayama, M. Arai; Burr formation in metal cutting; Annals of the CIRP, 36 (1) (1987), pp. 33-36

[4] M. Hashimura, K. Ueda, D. Dornfeld, K. Manabe; Analysis of Three-Dimensional Burr Formation in Oblique Cutting; CIRP Annals - Manufacturing Technology, Volume 44, Issue 1, 1995, Pages 27-30

[5] M. Hashimura, Y.P. Chang, D.A. Dornfeld; Analysis of burr formation mechanism in orthogonal cutting; Journal of Manufacturing Science and Engineering, 121 (1999), pp. 1-7

[6] Ken Lauderbaugh L. 2009. Analysis of the effects of process parameters on exit burrs in drilling using a combined simulation and experimental approach. Journal of Materials Processing Technology, Volume 209, Issue 4, 19 February 2009, Pages 1909-1919

[7] F. Klocke, S. Hoppe, R. Fritsch, FE-modeling of burr formation in orthogonal cutting, Proceedings of the Seventh International Conference on Deburring and Surface Finishing, University of California, Berkeley, 7-9 June, 2004, pp. 47-56.

[8] L.Ken Lauderbaugh Saunders, 2003. A finite element model of exit burrs for drilling of metals; Finite Elements in Analysis and Design, Volume 40, Issue 2, December, Pages 139158.

[9] Andrey Toropov, Sung-Lim Ko; A model of burr formation in the feed direction in turning ; International Journal of Machine Tools and Manufacture, Volume 46, Issue 15, December 2006, Pages 1913-1920

[10] Heisel U., Luik M., Eisseler R., 2005. Schaal M.. Prediction of Parameters for the Burr dimensions in Short-Hole Drilling CIRP Annals - Manufacturing Technology, Volume 54, Issue 1, Pages 79-82

[11] Schafer F., 1978, Gratbildung und Entgraten beim Umfangsstirnfrasen. VDI-Zeitung 120, 1/2: 47-55.

[12] Ko S-L, Lee J-K., 2001. Analysis of burr formation in drilling with a new-concept drill Journal of Materials Processing Technology, Volume 113, Issues 1-3, 15 June 2001, Pages 392-398

[13] Lee, E. H. et Shaffer, B. W. (1951). The theory of plasticity applied to a problem of machining. Transaction of the ASME, 73:405-413.

[14] A. Toropov, S.-L. Ko, B.-K. Kim; Experimental study of burrs formed in feed direction when turning aluminum alloy Al6061-T6; International Journal of Machine Tools and Manufacture, 45 (2005), pp. 1015-1022 
[15] L.M. Kachanov; Fundamentals of the Theory of Plasticity; Science, Moscow (1969)

[16] I.A. Khan, V. Bhasin, J. Chattopadhyay, A.K. Ghosh; On the equivalence of slip-line fields and work principles for rigid-plastic body in plane strain, International Journal of Solids and Structures, Volume 45, Issues 25-26, 15 December 2008, Pages 6416-6435

[17] Fikret KALAY 2007. Simulation numérique de l'usinage - Application à l'aluminium A2024-T351 - Techniques de l'ingénieur

[18] S.S. Pande, H.P. Relekar 1986 ; Investigations on reducing burr formation in drilling; International Journal of Machine Tool Design and Research, Volume 26, Issue 3, 1986, Pages $339-348$ 